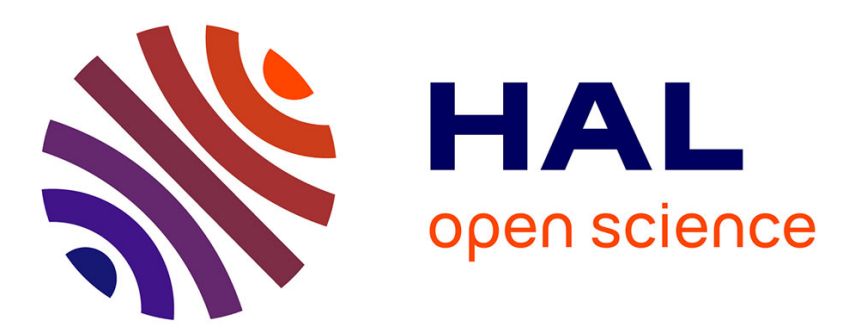

\title{
Association of HbA1c variability with atherosclerosis in diabetes: simple marker, risk factor or statistical bias?
}

Louis Monnier, Claude Colette

\section{To cite this version:}

Louis Monnier, Claude Colette. Association of HbA1c variability with atherosclerosis in diabetes: simple marker, risk factor or statistical bias?. Journal of Diabetes and its Complications, 2015, 29 (6), pp.745-746. 10.1016/j.jdiacomp.2015.05.002 . hal-01985794

\section{HAL Id: hal-01985794 https://hal.science/hal-01985794}

Submitted on 18 Jan 2019

HAL is a multi-disciplinary open access archive for the deposit and dissemination of scientific research documents, whether they are published or not. The documents may come from teaching and research institutions in France or abroad, or from public or private research centers.
L'archive ouverte pluridisciplinaire HAL, est destinée au dépôt et à la diffusion de documents scientifiques de niveau recherche, publiés ou non, émanant des établissements d'enseignement et de recherche français ou étrangers, des laboratoires publics ou privés. 


\section{Association of $\mathrm{HbA} 1 \mathrm{c}$ variability with atherosclerosis in diabetes: simple marker, risk factor or statistical bias?}

In this issue of the Journal of Diabetes and its Complications, Yang et al. (2015) report that HbA1c variability is significantly associated with the development of subclinical coronary atherosclerosis in type 2 diabetes and that this glycemic disorder is a greater predictor of premature coronary damages than mean $\mathrm{HbA} 1 \mathrm{c}$ at early stages of the disease. At first glance, this finding seems to provide an additional contribution to the debate that was opened by Kilpatrick, Rigby, and Atkin (2008). By retrospectively analyzing the data sets of the Diabetes Control and Complications Trial (DCCT) these authors showed that variability in $\mathrm{HbA} 1 \mathrm{c}$ adds to the mean $\mathrm{HbA} 1 \mathrm{c}$ in predicting the risk of microvascular complications in type 1 diabetes. Such observations were extended to type 2 diabetes by Sugawara et al. (2012), who have established that $\mathrm{HbA1c}$ variability predicts the development of microalbuminuria independently of mean $\mathrm{HbA} 1 \mathrm{c}$ in type 2 diabetes. However, the investigations of the associations between $\mathrm{HbA} 1 \mathrm{c}$ variability and diabetic complications were more often limited to microvascular complications in type 1 diabetes than extended to macrovascular outcomes in type 2 diabetes (Kilpatrick, 2012). Consequently, the report of an increased risk for macro- and micro-vascular events in type 2 diabetes, with worsening HbA1c variability (Hirakawa et al., 2014) is an important finding.

Reverting to the study of Yang et al. (2015), there arises the question as to whether long-term oscillations of $\mathrm{HbA} 1 \mathrm{c}$ around a mean $\mathrm{HbA} 1 \mathrm{c}$ value can be considered either a simple marker or a causative risk factor of premature atherosclerosis. Unfortunately, the study of Yang et al. (2015), which is observational in design, is unable to answer this question and to eliminate all the other confounding markers or risk factors. The main reason relates to the fact that the multiple logistic regression analysis used in this study is a statistical method, which is mainly designed for establishing associations between a series of "predictors" and a dependent variable (Zar, 1999). In the present study, the dependent variable is coded as either the presence or absence of subclinical coronary atherosclerosis. Apart from the age, which is considered a well-recognized risk factor for harmful vascular outcomes, Yang et al. (2015) have used and selected the following "predictors": i) those reflecting the overall glucose exposure and glycemic variability ii) those related to lipid disorders, and iii) those concerning specific treatments with either statins or insulin.

As expected, the age and duration of diabetes appear as the best "predictors", but the results are more questionable when the investigators (Yang et al., 2015) enter mean $\mathrm{HbA} 1 \mathrm{c}$ and $\mathrm{HbA} 1 \mathrm{c}$ variability as predictive variables using arbitrary models for the statistical analysis.

Conflicts of interest: The authors declare no conflicts of interest with the content of this editorial that was free from any funding.
For instance the mean $\mathrm{HbA} 1 \mathrm{c}$ never appears as a significant predictor when the $\mathrm{HbA} 1 \mathrm{c}$ variability is entered. In contrast, mean $\mathrm{HbA} 1 \mathrm{c}$ was statistically associated with the presence of subclinical coronary atherosclerosis when the HbA1c variability was deleted. These somewhat surprising and controversial results are probably due to a bias in the methodology of the multiple logistic regression analysis that requires first eliminating any intercorrelation between the "predictor" variables and secondly avoiding any arbitrary choice for the models selected in this analysis. For instance, it is highly likely that the ambient hyperglycemia and $\mathrm{HbA} 1 \mathrm{c}$ variability are positively intercorrelated. In addition, the selection of predictor variables should be done using a stepwise procedure in order to select the model, which is preferable to another. Finally, when we use a regression model, we ideally hope that there is a cause and effect relationship between the dependent variable and the predictive variables (Zar, 1999) Such an idyllic view is rarely confirmed because regression models are more descriptive than predictive. Bringing all these methodological limitations together, we suggest that the issue of the contribution of $\mathrm{HbA} 1 \mathrm{c}$ variability to the development of vascular complications, if it exists, cannot be simply solved by a multiple logistic regression analysis and more particularly when such an analysis is affected by statistical bias in methodology.

For that reason, such an issue would warrant to be addressed by implementing an interventional trial with an "optimal" design aimed at either confirming or refuting the aforementioned expected relationship. Ideally, such an interventional trial would involve a randomized controlled study with a long-term follow up period and parallel comparison between two groups of patients with type 2 diabetes, according to the guidances provided by the Food and Drug Administration, Center for Drug Evaluation and Research (2008). The first one should be assigned to dietary and pharmacological measures aimed at reducing the $\mathrm{HbA} 1 \mathrm{c}$ variability to its lower level and, ideally, at achieving a flat time course of the HbA1c profile. The patients assigned to the second group should be maintained on their usual dietary habits and standard antidiabetic treatments. Furthermore, in both groups, the therapeutic strategies should be aimed at achieving similar levels in mean $\mathrm{HbA} 1 \mathrm{c}$, plasma lipids and blood pressure. As it could be difficult to ensure a tight control of all these parameters over several years we should be very cautious about the reliability and pertinence of such long-term studies that have the ambitious goals of testing the impact of $\mathrm{HbA1c}$ variability on vascular outcomes, especially when many other risk factors can be involved as potential or real key players in the pathogenesis of diabetic complications (Gaede, Lund-Andersen, Parving, \& Pedersen, 2008; Laakso \& Lehto, 1997). In addition, the real cause of the improvement in vascular 
outcomes with $\mathrm{HbA} 1 \mathrm{c}$ flattening, if demonstrated, might remain uncertain because of the unavoidable lifestyle changes that could act as confounding factors.

Even though we have intuitively the feeling that long-term glycemic variability can exert harmful effects on vascular outcomes, this issue is not likely to be solved in the near future, as the designs of trials able to provide a clear answer are probably too complex and costly. So that the reader does not remain disappointed by the mixed conclusions of the present editorial, we would remind that even in "hard scientific domains" such as mathematics, several decades or centuries are sometimes required to elucidate theorems that could not be definitively demonstrated at the time they were proposed.

\section{References}

Food and Drug Administration, Center for Drug Evaluation and Research (2008). Guidance for industry: diabetes mellitus - evaluation cardiovascular risk in new antidiabetic therapies to treat type 2 diabetes. http://www.fda.gov/downloads/ Drugs/GuidanceComplianceRegulatoryInformation/Guidances/ucm071627.pdf

Gaede, P., Lund-Andersen, H., Parving, H. -H., \& Pedersen, O. (2008). Effect of a multifactorial intervention on mortality in type 2 diabetes. New England Journal of Medicine, 358, 580-591.

Hirakawa, Y., Arima, H., Zoungas, S., Ninomiya, T., Cooper, M., Hamet, P., et al. (2014). Impact of visit-to-visit glycemic variability on the risks of macrovascular and microvascular events and all-cause mortality in type 2 diabetes: The ADVANCE trial. Diabetes Care, 37, 2359-2365.
Kilpatrick, E. S. (2012). The rise and fall of HbA1c as a risk marker for diabetes complications. Diabetologia, 95, 2089-2091.

Kilpatrick, E. S., Rigby, A. S., \& Atkin, S. L. (2008). A1c variability and the risk of microvascular complications in type 1 diabetes. Diabetes Care, 32 2198-2202.

Laakso, M., \& Lehto, S. (1997). Epidemiology of macrovascular disease in diabetes. Diabetes Reviews,5, 294-315.

Sugawara, A., Kawai, K., Motohashi, S., Saito, K., Kodama, S., Yachi, Y., et al. (2012) $\mathrm{HbA} 1 \mathrm{c}$ variability and the development of microalbuminuria in type 2 diabetes. Diabetologia, 55, 2128-2131.

Yang, H. K., Kang, B., Lee, D.-H., Yoon, K.-H., Hwang, B.-H., Chang, K., et al. (2015) Association between hemoglobin A1c variability and subclinical coronary atherosclerosis in subjects with type 2 diabetes. Journal of Diabetes and its Complications, 29, 776-782.

Zar, J. H. (1999). Biostatistical analysis (Fourth ed.). Upper Saddle River, NJ, USA Prentice Hall, Inc, 663.

Louis Monnier* Claude Colette

Institute of Clinical Research, University of Montpellier 641 Avenue du doyen Giraud, 34093 Montpellier, Cedex 5,France *Corresponding author. Institute of Clinical Research University of Montpellier, 641 Avenue du doyen Giraud 34093 Montpellier Cedex 5, France Tel.: +33 411759891; fax: +33411759898 E-mail address: louis.monnier@inserm.fr 